Notfall Rettungsmed 2010 · 13:6-8

DOI 10.1007/s10049-009-1230-1

Online publiziert: 31. Januar 2010

(c) Springer-Verlag 2010
T. Groves

British Medical Journal, London
Peer review is used at many different stages of scientific discovery. It is essential to the approval and funding of research studies, staff, and departments; regulation and approval of new drugs and medical technologies; and selection of research for presentation at conferences. Journal peer review is probably the oldest example, however, and when Europe's first scientific journals were launched in 1665the Journal des Sçavans (later renamed Journal des Savants) and the Philosophical Transactions of the Royal Society of London-both used peer review. The International Committee of Medical Journal Editors (ICMJE) now defines journal peer review as "unbiased, independent, critical assessment...by experts who are not part of the editorial staff" and calls it an intrinsic part of all scholarly work. When peer review and editing are done well, readers can trust and use the published information in good faith. But to deserve such trust journals must ensure that peer review is fair and rigorous, and must help authors to fully and honestly report their work.

Most editors do their best, even though many have little relevant experience or training before taking on the role and often lack adequate support from publishers and journal owners. There are, at least, several international organisations that support and advise biomedical editors including the International Committee of Medical Journal Editors (ICMJE http://www. icmje.org), the World Association of Medical Editors (WAME http://www.wame. org/), the Council of Science Editors (CSE http://www.councilscienceeditors. org/), and the Committee on Publication Ethics (COPE http://publicationethics. org/). Authors can feel that their work is in safe hands, if they submit it to a journal that really follows these organisations' policies on fair, professional, and efficient editorial and peer review practices.

One reason that we can trust such editorial guidance is that it is based on evidence from peer review research. Much of this research has been presented at the international congresses on peer review and biomedical publication (which have taken place every four years since 1986) and then published in peer reviewed journals, and at the 2009 congress in Vancouver more than 100 studies evaluating the processes and outputs of peer review were presented (http://www.ama-assn.org/ public/peer/peerhome.htm). From all of this evidence, we know that peer review can improve the quality, trustworthiness, and clarity of scholarly biomedical publications, and so, despite its limitations, we continue to use it.

What are the limitations of peer review? Firstly, it can be difficult and expensive to set up and run. More importantly, peer review can be slow, overly conservative, unreliable, poor at detecting errors and misconduct, open to abuse, skewed towards positive results, biased by conflicts of interest, and systematically biased against authors' ideas, reputations, locations, and even gender [1]. Journals have tried several ways to minimise bias in peer review. One approach is to remove authors' names and addresses from manuscripts. This puts authors and reviewers in the same position, given that most journals also mask reviewers' identities. Relatively few journals use such double blind review, however: it is awkward to do and, anyway, several studies have shown that around a third of the time reviewers correctly guess the authors' identities. This is probably because they were already aware of the work or they noticed the authors' earlier work cited prominently in the article.

Another approach is to do the opposite and open up peer review so that reviewers, editors, and authors all know each other's identities. The usual objection to openness is that peer reviewers will be too fearful of professional rivalries and reputations to take part in a system that demands signed reviews, and will either refuse completely or will provide only bland and uncritical comments. Responses to a recent online survey (of more than 4000 science reviewers but with an overall response rate of just over $10 \%$ and, therefore, possible non-response bias) suggest that reviewers prefer anonymity: $76 \%$ favoured the double blind system where only the editor knows who the reviewers are [2].

In a randomised, controlled trial at the BMJ, open review did not reduce the scientific quality of the reviewers' reports and it improved their tone [3]. The BMJ subsequently adopted this approach in the spirit of making scientific discourse constructively critical and open, and so did a few other journals. These include the Journal of the Royal Society of Medicine, whose editor Kamran Abbasi (who was formerly at the BMJ) has argued that "journals are locked in an end- 
less struggle between secrecy and openness - and the more often openness can triumph the better... open peer review makes reviewers more courteous and less inclined to torpedo a paper with emotional - and sometimes offensive - arguments." Our experience at the BMJ over the past decade reinforces these sentiments, and we very rarely have difficulty in engaging reviewers or find problems arising from open review. PLoS Medicine, however, has retreated from open review. In the journal's first two years the editors asked reviewers to provide either a signed review or a reason for not signing, but they discontinued this practice in late 2007 saying "when asked why they wish to remain anonymous, reviewers provide comments such as "fear"; "this author is not a forgiving person"; that they do not wish to be contacted directly by authors; and perhaps the most common: "s/he reviews my grants."

At the BMJ we have also evaluated an extended kind of open review: making reviewers' reports (with their consent) available to readers as part of an online prepublication history alongside each research paper. The study on this has not yet been published, however, and we are not yet routinely posting articles' prepublication histories. Meanwhile, the medical journals in the BMC series published by BioMed Central have adopted this approach. Other journals' experiments have gone even further, by posting provisionally accepted articles online and inviting reviews from the general community of readers. For example, the Medical Journal of Australia [3] and Nature [5] used and conducted studies of this approach, but responses from their communities were limited and both journals concluded that this was no substitute for formal, traditional peer review by experts.

As scientific discourse and publication increasingly use the web, spontaneous online open review may become more acceptable. It is certainly becoming technically easier, with the advent of web applications such as Google knol (http://knol.google.com/k): this enables the posting of open access scholarly articles or knols ("units of knowledge") that readers can rate and comment on. PLoS Currents: Influenza (http://knol.google. $\mathrm{com} / \mathrm{k} / \mathrm{plos} /$ plos-currents-influenza) is effectively a free open access online journal that uses knols, and describes itself as "a website for rapid and open sharing of useful new scientific data, analyses, and ideas in all aspects of influenza research [where]... all content is moderated by an expert group of influenza researchers, but in the interest of timeliness, does not undergo in-depth peer review."

Such approaches may help to minimise bias in peer review, but they give little control over the quality of reviews. At the BMJ we ask reviewers to advise us on the importance, originality, and relevance of each study's research question and to comment in detail on whether that question has been answered using the right methods: only then do we want to hear the reviewers' views on the study's results and their meaning. From several blinded studies we also know which type of reviewers tend to deliver the best opinions. They are reviewers who work in reputable institutions and understand statistics and epidemiology-although, perhaps surprisingly, they are generally aged under 40 and are not yet in the most senior posts [6].

The quality of a journal depends on more than its peer review process, of course: its content is of paramount importance. Obviously, a good article has to start with good work, whether that comprises collation of scholarly ideas or some original research. For a review article the quality of the content depends on the author's professional knowledge and his or her use of evidence, preferably acquired by searching the literature with an open and critical mind. Usually, the objectivity and currency of the article will be greater if the evidence is sought systematically, and ideally with the help of a librarian. An article that reports a clinical practice guideline presents a different challenge: as well as giving clear recommendations, the article should explain how the evidence was assembled and appraised using consensus, and should rate the strength and reliability of that evidence. This will help editors, reviewers, and readers to appraise the guidelines. More importantly, clinical practice guidelines should have maximum reliability, clarity, and transparency because they are often highly influential to medical practice and policy, and need to be trustworthy. This is why some journals ask authors to follow specific guidance, for example the GRADE system (http://www.gradeworkinggroup.org), when developing and writing clinical practice guidelines.

Reviews and guidelines are just two examples of medical writing. There is plenty of general advice on the web on how to write all kinds of scholarly medical articles. The most influential resource is the Uniform Requirements for Manuscripts Submitted to Biomedical Journals, launched 30 years ago by ICMJE. The initial aim of this unified advice was to lessen the effort and inconvenience of having to completely reformat a manuscript when submitting it to one ICMJE member journal after rejection from another. These uniform requirements have now been adopted by more than 800 journals. Over time the requirements have evolved beyond guidance on article format to encompass wider policies and advice on good publication practice and ethics. They have been complemented and echoed by guidance from WAME, CSE, and COPE and, in turn, by journals' own advice to authors.

For authors writing research papers, the EQUATOR website (Enhancing the QUAlity and Transparency Of health Research www.equator-network.org/) provides invaluable advice. EQUATOR brings together in one free website a wide range of specific guidance on writing research papers, called"reporting guidelines." Reporting guidelines specify a minimum set of items that authors should use to give a clear and transparent account of the design, conduct, and findings of each type of biomedical research study. They often include a checklist and flowchart to help authors describe their study in the necessary detail, focusing particularly on elements that might have introduced bias. Not surprisingly, reviewers and editors find these checklists and flowcharts very helpful, and many journals now ask authors to use them when preparing and submitting research papers (at the BMJ we make it clear to authors that we will not send research articles for external review until we have received the appropriate checklist and flowchart). 
Ideally, journal peer review for research papers should include statistical appraisal of the study design and the analyses. Editors do not always have such expertise or access to statisticians, but asking authors to follow reporting guidelines such as the CONSORT (Consolidated Standards of Reporting Trials) and STROBE (Strengthening the Reporting of Observational Studies in Epidemiology) statements does, at least, ensure that the methods and results are clearly and fully reported and are therefore easier for everyone to evaluate.

Transparency is important at every stage of research-from planning the research through to its publication and dissemination. Registration, publication, and publicly available reporting of health research, particularly for clinical trials, are now mandated by many sponsors and funders. The US Food and Drug Administration (FDA) Amendments Act of 2007 requires researchers to register at clinicaltrials.gov all trials of products which need FDA approval, and the European Commission has introduced this year similar regulations for registering paediatric trials and their results in the European Union Drug Regulating Authorities Clinical Trials (EudraCT) database, with plans to extend this to adult trials soon. In addition the World Health Organization has developed a minimum dataset for trial registration, so that all registries contain roughly the same information about trials, and has built a web platform to facilitate access to the major national and international trial registries (www.who. int/ictrp/). Editors have also played an important part in supporting trial registration. ICMJE encourages all biomedical journals to adopt a policy, whereby only registered clinical trials will be considered for publication and ICMJE's member journals now refuse to consider unregistered trials. Although all of these policies currently apply specifically to clinical trials there is increasing interest in registering all health research, including observational studies.

Journals cannot fully deserve readers' trust without asking authors and reviewers to declare any relevant conflicts of interest. "Financial conflicts of interest threaten patient care, taint medical informa- tion and raise costs. They create deception, impair physicians' judgement and reduce their willingness to be their patients' advocates." So wrote Jerome P Kassirer, former editor-in-chief of The New England Medical Journal, in his book "On the Take: How Medicine's Complicity with Big Business Can Endanger Your Health" (Oxford University Press 2004). Editors cannot make people tell the truth, but they should certainly try. So the ICMJE Uniform Requirements for Manuscripts Submitted to Biomedical Journals say that all participants in the peer review and publication process [and, by implication, this includes editors] must disclose all relationships that could be viewed as potential conflicts of interest, and recommend that journals publish authors' statements of competing interests when these might affect the way the work is judged by readers.

To make the process of disclosure of competing interests easier for authors and less confusing for readers, ICMJE has now produced a single disclosure form that has been adopted by all of its 12 member journals (www.icmje.org/coi_disclosure. pdf). This form asks authors to disclose information on their associations with commercial entities that provided support for the work reported in the submitted manuscript, their associations with commercial entities that could be viewed as having an interest in the general area of the manuscript in the 36 months before submission, any similar financial associations involving their spouse or children, and any nonfinancial associations that may be relevant to the manuscript. Until 10 April 2010 these journals will be piloting the new form and asking for feedback on it; after that it will be amended, if necessary, and then formally recommended in the uniform requirements.

Despite all of these efforts to improve peer review and editorial practice, these are human processes that will always have flaws. As Drummond Rennie, deputy editor of JAMA, observed, paraphrasing Winston Churchill, "Peer review is like democracy, which is the worst form of government except all those other forms that have been tried from time to time." corresponding address

\section{T. Groves}

British Medical Journal

WC1H 9JR London, UK

tgroves@bmj.com

Conflict of interest. Trish Groves is the senior research editor at the $\mathrm{BMJ}$ and is responsible for running the journal's peer review process. She is also a member of the council of the Committee on Publication Ethics (COPE) and a contributor to the forthcoming CONSORT 2010 (Consolidated Standards of Reporting Trials) and SPIRIT (Standardized Protocol Items for Randomized Trials) statements.

\section{References}

1. Jefferson T, Rudin M, Brodney Folse S, Davidoff $F$ (2007) Editorial peer review for improving the quality of reports of biomedical studies. Cochrane Database Syst Rev 2:MR000016

2. Sense about Science. Peer Review Survey 2009: preliminary findings; URL: http://www. senseaboutscience.org.uk/index.php/site/project/395

3. van Rooyen S, Godlee F, Evans S, Black N, Smith $R$ (1999) Effect of open peer review on quality of reviews and on reviewers' recommendations: a randomised trial. BMJ 318:23-27

4. Bingham CM, Higgins $G$, Coleman R, van der Weyden MB (1998) Medical Journal of Australia internet peer-review study. Lancet 352:441445

5. Greaves S, Scott J, Clarke M, Miller L, Hannay T, Thomas A, Campbell P (2006) Nature's trial of open peer review. Nature doi:10.1038/nature05535; URL: http://www.nature.com/nature/peerreview/debate/nature05535.html

6. Black N, van Rooyen S, Godlee F, Smith R, Evans $S$ (1998) What makes a good reviewer and a good review in a general medical journal. JAMA 280:231-233 